\title{
Uma análise da coesão textual e da estrutura narrativa em textos escritos por adolescentes surdos ${ }^{1}$
}

\author{
Viviany Meirelles \\ Alina Galvão Spinillo \\ Universidade Federal de Pernambuco
}

\begin{abstract}
Resumo
Considerando que os surdos utilizam diferentes formas de comunicação, investigou-se se tal fator influenciaria a produção escrita de textos. Quarenta adolescentes surdos com perda auditiva profunda, alunos de $5^{\mathrm{a}}$ à $7^{\underline{a}}$ série do ensino fundamental foram igualmente divididos em dois grupos: usuários da LIBRAS e surdos oralizados. A partir de uma seqüência de gravuras, cada participante produziu uma história escrita que foi analisada quanto à qualidade da estrutura narrativa e quanto ao estabelecimento de cadeias coesivas. Os resultados mostraram que a coesão textual é um problema para os surdos, não havendo diferenças entre os grupos. Embora as produções apresentassem limitações quanto à estrutura narrativa, verificou-se que um maior número de surdos oralizados produzia histórias mais elaboradas do que os usuários da LIBRAS. As diferenças entre grupos e dificuldades encontradas são interpretadas a partir do pouco contato que os surdos têm com textos em seu cotidiano. Implicações educacionais são discutidas.
\end{abstract}

Palavras-chave: adolescentes surdos; produção de textos; linguagem oral e de sinais

\begin{abstract}
Textual cohesion and narrative structure in written texts produced by deaf adolescents. Deaf individuals use different forms of communication: oral language and sign language. This study investigated whether these forms of communication would have an effect on text production. Forty deaf adolescents were equally divided into two groups: those who used sign language (LIBRAS) and those who used Portuguese in its oral form. Each participant was asked to write a story from a sequence of pictures. The stories were analyzed according to their cohesiveness and to their narrative structure. It was found that both groups had difficulties in establishing textual cohesion in their stories. Although both groups produced stories with an elementary structure, deaf adolescents who used oral language produced stories more elaborated than those who used sign language. Differences between groups and the difficulties the participants had are interpreted as a function of their limited contact with written texts in their everyday life. Educational implications are discussed.
\end{abstract}

Key words: deaf adolescents; text production; oral and sign language

I nvestigações sobre as habilidades lingüísticas dos surdos se concentram no exame das habilidades de comunicação, havendo poucos estudos acerca do conhecimento que esta população apresenta sobre a compreensão e a produção de textos. A importância desse conhecimento tem sido cada vez mais reconhecida, tanto na pesquisa em psicologia como em educação, como indicam os Parâmetros Curriculares Nacionais (PCN) de Língua Portuguesa (Brasil, 1997). Da mesma forma que habilidades de compreensão e de produção de textos são consideradas cruciais para o domínio da língua materna entre indivíduos ouvintes, estas também devem ser consideradas cruciais para indivíduos surdos. No entanto, pouco, ainda, se sabe acerca das habilidades textuais desta população, sendo necessária a realização de estu- dos que contribuam para a construção de um quadro de informações mais preciso e informativo. Neste contexto, a presente investigação trata da produção de textos escritos por adolescentes surdos.

Um outro aspecto a considerar em pesquisas com esta população é o fato de que os surdos utilizam diferentes formas de comunicação. Torna-se, portanto, interessante investigar se essas diferentes formas de comunicação influenciariam as habilidades textuais de seus usuários. Para examinar esta possibilidade, os surdos participantes deste estudo foram divididos em dois grupos: um constituído por surdos usuários da Língua Brasileira de Sinais (LIBRAS) ${ }^{2}$ e outro por um grupo de surdos oralizados, usuários da Língua Portuguesa na modalidade oral. 


\section{As formas de comunicação dos surdos}

São três as principais formas de comunicação adotadas pelos surdos, as quais são brevemente tratadas a seguir.

\section{A língua de sinais}

Considerada a língua natural dos surdos (Almeida, 2000), a língua de sinais possui características próprias, utilizando os gestos e expressões faciais como canal de comunicação substituto da vocalização. A aquisição desta modalidade de comunicação tem sido objeto de inúmeras investigações com crianças de diferentes ambientes lingüísticos: surdos filhos de pais surdos, surdos filhos de pais ouvintes e ouvintes filhos de pais surdos. A partir desses estudos foram identificadas fases que marcam o processo de apropriação da língua de sinais por parte de seus usuários: inicialmente gestos sem um significado preciso; posteriormente sinais específicos relacionados a objetos, adquirindo, então, um significado estável; até um momento em que vários sinais se combinam para formar uma sintaxe.

Nas línguas de sinais, a palavra é denominada sinal. Este é formado a partir da combinação do movimento das mãos com um determinado formato em uma determinada localização do corpo (uma parte ou um espaço em frente ao corpo). Estas articulações das mãos, comparáveis aos fonemas e às vezes aos morfemas, são denominadas parâmetros ${ }^{3}$. Felipe (1988; 1998) e Ferreira Brito (1995) afirmam que as línguas de sinais se estruturam a partir de unidades mínimas que formam unidades maiores e mais complexas, possuindo diversos níveis lingüísticos: fonológico, morfológico, sintático, semântico e pragmático.

A questão levantada por inúmeros estudiosos na área é se esta forma de comunicação visual pode ou não ser considerada como língua. Recentemente, os pesquisadores demonstraram que a língua de sinais não apenas satisfaz as necessidades cognitivas, comunicativas e expressivas de seus usuários, como também apresenta todas as propriedades fundamentais de uma língua.

Segundo Stockoe (1960), Ferrari (1990) e Ferreira Brito (1995), dentre outros, as línguas de sinais são comparáveis em complexidade e em expressividade às línguas orais, pois possuem estrutura e regras gramaticais próprias ${ }^{4}$, tendo, assim, valor lingüístico semelhante às línguas orais.

\section{O oralismo}

O princípio básico da filosofia oralista, como afirmado por Almeida (2000), é que deve ser dada ao surdo a oportunidade para comunicar-se através da fala, aproximando-o e integrando-o à comunidade de ouvintes, aproveitando o resíduo auditivo apresentado através de aparelhos (amplificadores auditivos) e de treinamentos que estimulam a oralidade (e.g., método acupédico, verbotonal). Diversas técnicas têm sido desenvolvidas com esse objetivo, como é o caso da eletroacústica (aparelhos de amplificação sonora individual e coletiva para um maior aproveitamento dos resíduos auditivos). Os surdos oralizados seriam, portanto, aqueles que se comunicam oralmente através da língua materna, como qualquer indivíduo ouvinte.

\section{O bilingüismo}

Atualmente, o bilingüismo tem sido amplamente aceito entre os especialistas e educadores como a forma de comunicação dos surdos que permite “... a integração do indivíduo ao meio sociocultural a que naturalmente pertence, ou seja, às comunidades de surdos e de ouvintes.” (Fernandes, 1997, p. 309). Além disso, há estudiosos, como Ferreira Brito (1989), que afirmam que a aquisição da língua oral pelos surdos seria um meio facilitador da aquisição da escrita.

O pressuposto básico é de que os surdos devem adquirir como língua materna a língua de sinais; e como segunda língua, a língua oral oficial de seu país; no caso do Brasil, o português. Os surdos bilíngües seriam então, oralizados e, ao mesmo tempo, usuários da língua de sinais. De acordo com Moura (2000), os surdos formam uma comunidade com cultura e língua próprias, e o bilingüismo permite, portanto, que o indivíduo não perca sua identidade com esta comunidade através da língua dos sinais; e, ao mesmo tempo, permite que o surdo não se distancie da comunidade de ouvintes (através da língua oral), ampliando, assim, seu universo de interação.

Alguns estudiosos aceitam a idéia de que a língua de sinais pode atuar como um apoio para a oralidade, de maneira que a combinação de ambas as modalidades possa garantir formas de comunicação mais eficientes, idéia esta amplamente aceita entre os partidários da comunicação bimodal, também denominada comunicação total.

Dorziat (1997) considera a comunicação total uma variação importante dessas formas de comunicação, em que se combinam, simultaneamente, a língua de sinais, a oralidade, os gestos naturais e as expressões faciais. A comunicação total, devido à combinação entre as diferentes formas de comunicação, gera alterações estruturais tanto na língua oral como na língua de sinais. A principal diferença entre a comunicação total e o bilingüismo é que o surdo bilíngüe é usuário de duas línguas, utilizando-se de uma ou de outra para comunicar-se, em função do seu interlocutor (se um surdo oralizado ou um ouvinte, ou se um usuário de língua de sinais), enquanto a comunicação total é uma forma híbrida de comunicação com um mesmo interlocutor. Neste sentido, como afirma Dorziat, a comunicação total não pode ser entendida como uma língua propriamente dita, mas uma maneira de comunicar-se ou mesmo uma metodologia específica para o ensino dos surdos. Observa-se que a comunicação total favoreceu a inclusão dos surdos em escolas regulares, visto que facilitou a comunicação do professor (que não dominava a língua de sinais) com alunos surdos e, conseqüentemente, facilitou as situações de instrução desses alunos.

No que concerne às pesquisas desenvolvidas com esta população, verifica-se que os estudos procuram comparar o desempenho de surdos oralizados e de surdos usuários de língua de sinais com o propósito de examinar se haveria diferenças entre os dois grupos quanto a aspectos cognitivos e lingüísticos, como apresentado a seguir.

\section{Pesquisas com surdos}

Pesquisas que versam sobre habilidades intelectuais (e.g., Schelesinger \& Meadow, 1972) indicam que as limita- 
ções identificadas entre os surdos decorrem muito mais de dificuldades metodológicas em acessar as reais habilidades cognitivas dessa população e de limitações lingüísticas do que, de fato, de um déficit intelectual. O potencial intelectual dos surdos é considerado normal, embora seu desempenho seja limitado pela privação de ferramentas lingüísticas. De acordo com Fernandes (1990), a ausência de linguagem pode provocar um atraso na aquisição de vários aspectos cognitivos, porém este atraso não deve ser interpretado como uma real incapacidade intelectual.

Um exemplo das habilidades dos surdos é o estudo realizado por Cordeiro e Dias (1995) sobre raciocínio lógicodedutivo. Adolescentes, com idades entre 14 e 20 anos, foram divididos em três grupos: ouvintes, surdos oralizados e surdos usuários da LIBRAS. Cada participante era solicitado a resolver problemas silogísticos que consistiam em duas premissas e uma conclusão sob forma de pergunta. Justificativas eram solicitadas após a resolução de cada problema. Em relação aos usuários da LIBRAS, as entrevistas foram feitas por um intérprete. Os problemas silogísticos eram de três tipos: silogismos com conteúdos congruentes (fatos conhecidos que concordavam com a experiência dos participantes); silogismos com conteúdos incongruentes (fatos contrários à experiência) e silogismos com conteúdos desconhecidos (fatos desconhecidos, porém coerentes com a realidade). Nos problemas com conteúdos incongruentes, metade dos participantes em cada grupo recebeu os silogismos na forma clássica (como pequenas histórias) e a outra metade com a instrução de faz-de-conta (apelo a um mundo imaginário, de fantasia, em que tudo é possível). Os participantes dos três grupos resolveram os problemas silogísticos, fornecendo justificativas teóricas (as mais elaboradas). Concluiu-se que os surdos, da mesma forma que os ouvintes, eram capazes de raciocinar silogisticamente a partir de fatos contrários e desconhecidos, mesmo sem o suporte do contexto de fantasia, contexto este que, em estudo anterior, havia mostrado ter um efeito facilitador na resolução de problemas silogísticos por crianças ouvintes.

Esse resultado mostrou que, apesar das limitações lingüísticas, os surdos raciocinam silogisticamente. Isso era observado mesmo entre os surdos usuários da LIBRAS, indo de encontro à idéia de que estes, por não dominarem a linguagem oral, apresentam limitações no desenvolvimento do pensamento lógico-abstrato, como sugerido por alguns autores (e.g., Caquette, 1973; Oléron, 1972, citado por Cordeiro \& Dias, 1995).

Fernandes (1990) conduziu uma investigação sobre a compreensão de textos escritos em 40 portadores de surdez profunda (maiores de 18 anos, com escolaridade variando da quarta à oitava série do ensino fundamental). Após a leitura de dois textos, solicitava-se a reprodução oral ou em língua de sinais e a reprodução escrita do texto apresentado. Os dados mostraram que os participantes possuíam muito mais dificuldades na reprodução escrita do que na reprodução oral ou em língua de sinais. Cerca de 50\% dos participantes compreendia adequadamente o texto ou, pelo menos, a idéia principal nele veiculada; no entanto, a grande maioria não expres- sava esta mesma compreensão quando na reprodução escrita que era bastante limitada. A autora comenta que os surdos, de maneira geral, não estão preparados para realizar atividades de compreensão de textos, possivelmente, devido à ausência dessa atividade nas situações escolares.

A partir de um outro tipo de metodologia, Santos e Dias (1998) investigaram a compreensão de textos em 48 adolescentes surdos com idades entre 12 e 20 anos com nível de escolaridade até a $8^{\underline{a}}$ série, divididos em três grupos: ouvintes, surdos usuários da LIBRAS e surdos oralizados. Cada participante era solicitado a: (a) responder perguntas sobre informações literais e inferenciais relativas a uma história apresentada; e (b) fornecer um título para a história. Os resultados mostraram que os surdos oralizados tiveram mais dificuldades em compreender o texto do que os usuários da LIBRAS e os ouvintes. Em relação às perguntas, de modo geral (diferenças significativas não foram encontradas entre perguntas literais e inferenciais no interior de cada grupo), os oralizados obtiveram um percentual de acertos inferior aos ouvintes e usuários da LIBRAS. Quanto ao fornecimento de títulos, observou-se que os ouvintes e usuários da LIBRAS forneciam um maior percentual de títulos precisos do que os surdos oralizados que tendiam a fornecer títulos incongruentes que não possuíam uma relação com a história apresentada. De modo geral, os surdos usuários da LIBRAS tiveram um desempenho mais próximo dos adolescentes com audição normal do que os surdos oralizados. A interpretação das autoras quanto à diferença entre surdos oralizados e surdos usuários da LIBRAS foi que a língua sinalizada seria uma língua de referência para o surdo, atuando como um suporte lingüístico que facilitaria a compreensão de textos.

A produção escrita de textos por surdos foi investigada por Góes (1996) no contexto de sala de aula com alunos de 14 a 26 anos do ensino supletivo. Os textos escritos foram produzidos ao longo de vários meses a partir de atividades em que os alunos podiam recorrer à ajuda da professora. As produções apresentavam diversos desvios das regras de construção do português: uso inadequado e omissão de preposições, terminação verbal que não correspondia à pessoa e ao tempo do verbo, inconsistências entre passado e presente, flexão inadequada de gênero (adjetivos, artigos) e uso incorreto do pronome pessoal.

Os textos foram analisados, ainda, quanto à coesão textual, verificando-se o uso de referências ambíguas em relação aos pronomes pessoais e possessivos, gerando prejuízos na interpretação. A compreensibilidade do texto era comprometida não apenas pelo uso inapropriado de elos coesivos, mas, também, pela inclusão de palavras inventadas com significados não convencionais, e por uma ausência de conexão entre as partes do texto. Góes (1996) concluiu que, mesmo havendo passado por um longo período de escolarização, os surdos apresentam dificuldades com a escrita, dificuldades essas decorrentes do uso restrito da linguagem escrita por essa população em seu cotidiano.

Conte, Rampelli e Volterra (1996) também investigaram a escrita de textos em surdos, através de um estudo de caso de uma menina surda de 13 anos, oralizada. Após alguns en- 
contros com Silvia, as pesquisadoras passaram a utilizar a língua de sinais como suporte para a linguagem oral que se mostrava insuficiente para garantir uma comunicação mais clara durante os encontros. Aos poucos ela familiarizou-se com a combinação de ambas as modalidades de comunicação. Durante os encontros, um total de 14 no período de seis meses, Silvia foi ensinada a usar um processador de palavras para trabalhar com textos (contos de fadas). As atividades envolviam leitura de textos, respostas a perguntas e comentários sobre eles, reprodução escrita dos textos no computador, revisão textual e produções livres sobre experiências pessoais. As dificuldades iniciais observadas referiam-se à concordância verbal, uso de verbos, ausência de pontuação e de letras maiúsculas. As reproduções feitas, entretanto, indicavam que a menina tinha habilidade em utilizar no texto reproduzido a mesma seqüência temporal de eventos presentes na história lida. As reproduções feitas eram analisadas com Silvia, de forma que eram apontados e discutidos os erros apresentados, sendo fornecidas explicações para esclarecê-los. Dificuldades foram também detectadas quanto ao uso do discurso direto (diálogos) e indireto relativo aos personagens das histórias e em relação ao fato de que os textos reproduzidos não permitiam diferenciar o narrador da história dos personagens nela presentes. Para superar essas limitações foram fornecidas intervenções que envolviam a identificação dos personagens. Observou-se, ainda, que Silvia, ao compor textos, tendia a usar frases isoladas em que se repetia inúmeras vezes o nome dos personagens. Com o auxílio do computador, as frases produzidas eram colocadas em destaque, sendo feitas sugestões no sentido de substituir as repetições por pronomes e de juntar as frases através de conjunções de forma a estabelecer elos de ligações entre os personagens, as ações realizadas e os eventos narrados. No decorrer dos encontros observou-se, gradativamente, o uso de letras maiúsculas e o emprego da concordância verbal. Ao final dos encontros observou-se que ela era capaz de organizar, no texto escrito, uma seqüência de idéias e conectá-las de forma apropriada, sendo suas histórias mais coesas e coerentes. O uso da pontuação passou a ser mais freqüente. No entanto, ainda tinha dificuldades na escrita espontânea de textos. Este estudo de caso mostra que houve uma melhora nas habilidades lingüísticas de Silvia. Este progresso parece ter sido decorrente tanto da natureza da intervenção proposta como da possibilidade de comunicar-se através de diferentes ferramentas (linguagem oral, língua dos sinais e computador).

Um outro aspecto investigado na produção de textos por crianças surdas foi a pontuação. Ruiz (1997) realizou um estudo de caso com uma criança surda desde sua alfabetização. Quando Elena perdeu a audição, os pais optaram pelo inglês sinalizado, porém os sinais de pontuação sempre foram enfatizados durante o diálogo. Por exemplo, quando a mãe, oralmente, concluía uma pergunta, fazia um sinal, indicando que estava perguntado algo. Além disso, Elena era amplamente estimulada a ler livros variados e a escrever. Aos poucos surgiram sinais de pontuação em suas produções escritas, sinais esses cada vez mais freqüentes e empregados de maneira adequada. O que se observou foi que a surdez dificulta, porém, não impede que a criança que não possui um apoio auditivo empregue apropriadamente as marcas de pontuação. Segundo a autora, existem estratégias, além das auditivas, que podem ser usadas para pontuar, como estratégias pragmáticas, semânticas e morfossintáticas que precisam ser enfatizadas quando da aprendizagem da pontuação pelo surdo. A autora comenta que quanto maior o contato e domínio da língua escrita por parte do indivíduo surdo, maior será sua habilidade com relação à pontuação, sendo capaz de, mesmo sem o apoio auditivo, criar hipóteses acerca dos usos e funções das marcas de pontuação.

De modo geral, as pesquisas acima discutidas indicam que os surdos apresentam dificuldades na construção de textos que possam ser interpretados por um leitor. Tendo em vista os poucos estudos sobre produção de textos nesta população e dada a importância de tal habilidade no desenvolvimento da linguagem, a presente investigação volta-se para o exame da produção escrita de histórias em adolescentes surdos. Dois aspectos relativos à textualidade são abordados: a coesão textual - a partir do exame do estabelecimento de cadeias coesivas, e a estrutura narrativa própria de histórias. Além de analisar as características de textos escritos por surdos quanto a esses dois aspectos, o estudo procurou investigar se a modalidade de comunicação por eles adotada (português oral e LIBRAS) influenciaria a produção escrita de textos.

\section{Método}

\section{Participantes}

Quarenta adolescentes surdos, com idades entre 14 e 19 anos, cursando de $5^{\underline{a}}$ à $7^{\underline{a}}$ do ensino fundamental, alunos de escolas e centros de reabilitação em Recife e Fortaleza. A escolha dessas séries deveu-se ao fato de que apenas a partir da $5^{\underline{a}}$ série é que os participantes estavam aptos a escrever textos. Os participantes apresentavam perda auditiva profunda (a partir de $91 \mathrm{~dB}$ ), bilateral, congênita ou adquirida até o final do segundo ano de vida. A amostra foi igualmente dividida em dois grupos: um grupo (média de idade: 17a 1m) formado por surdos usuários da LIBRAS, e o outro grupo (média de idade: 16a 2m) por surdos oralizados.

\section{Procedimento}

Em sala de aula, cada participante era solicitado a produzir por escrito uma história a partir de uma seqüência de gravuras. A tarefa foi aplicada em uma única ocasião com duração de aproximadamente 35 minutos. As instruções endereçadas aos usuários de LIBRAS foram fornecidas pelo professor através do português sinalizado; enquanto as instruções endereçadas aos oralizados foram dadas, oralmente, pelo examinador.

\section{Material}

Folha de papel, lápis e borracha, seqüência de gravuras (ver Apêndice) que era a mesma utilizada por Shapiro e Hudson (1997). Optou-se por uma seqüência de gravuras como estímulo para a produção da história com vistas a garantir que o tema, os personagens e os episódios fossem 
mantidos constantes. Para alguns autores (e.g., Brandão \& Spinillo, 2001; Hudson \& Shapiro, 1991), este controle é fator importante na produção de textos e em sua posterior comparabilidade. Além disso, em estudo piloto aplicado observou-se que os surdos tinham grande dificuldade em produzir textos na ausência de gravuras, mesmo quando um tema era fornecido. Importante mencionar que a seqüência de gravuras apresentava uma situação-problema a ser resolvida pelos personagens. Segundo Shapiro e Hudson (1997), Lins e Silva e Spinillo (2000) e Spinillo (2001), histórias produzidas a partir de seqüência de gravuras que contém uma situaçãoproblema são mais elaboradas do que histórias produzidas a partir de seqüência de gravuras que indicam eventos que se sucedem temporalmente. Assim, procurou-se oferecer aos participantes uma situação favorável à produção de histórias, isto é, seqüência de gravuras com um situação-problema.

\section{Análise dos dados}

\section{A coesão textual investigada a partir de cadeias coesivas}

De acordo com teóricos da lingüística textual (e.g., Fávero \& Koch, 2000; Koch, 1989), a coesão é um dos princípios constitutivos da textualidade que se expressa através de marcas lingüísticas na superfície do texto, assegurando-lhe a continuidade, a seqüência e unidade de sentidos.

Segundo Halliday e Hasan (1976), a coesão está relacionada ao modo como o texto se estrutura semanticamente, referindo-se às relações de significado que se estabelecem, fazendo com que o texto seja mais do que uma seqüência de frases. A coesão permite a interpretação de um elemento no discurso que é dependente de um outro que o antecede (coesão anafórica) ou que o segue (coesão catafórica).
Para Marcuschi (1983), os fatores que regem a conexão seqüencial (a coesão) “... dão conta da estruturação da seqüência superficial do texto; não são simplesmente princípios sintáticos e sim uma espécie de semântica da sintaxe textual, onde se analisa como as pessoas usam os padrões formais para transmitir conhecimentos e sentidos” (p. 25).

Perspectiva semelhante é compartilhada por Antunes (1996) que afirma que a coesão se refere à organização dos elementos na superfície do texto de modo a promover a continuidade, a progressão e a unidade semântica subjacente. A autora aponta duas propriedades essenciais da coesão: uma é promover e assinalar a continuidade da organização superficial do texto; e a outra é o estabelecimento dos fundamentos macro-estruturais que garantem a unidade tópica do texto. Estas funções relacionam-se com a dimensão local dos vários segmentos textuais e com a dimensão global do texto.

A partir de uma análise da coesão em textos jornalísticos publicados na mídia impressa, a autora acrescenta à literatura uma nova e importante perspectiva acerca da coesão textual quando introduz o conceito de cadeia coesiva. Cadeia coesiva é definida como um encadeamento de nexos semanticamente semelhantes que se distribuem pela superfície do texto, como se este se constituísse em um terreno pontilhado por tipos de nós, formando uma rede de significados (Antunes, 1996). A formação de cadeias coesivas ocorre quando um determinado item lexical que aparece pela primeira vez (matriz) é repetido ou substituído ao longo do texto por outros léxicos (seus referentes).

Diversas cadeias coesivas foram identificadas pela autora, sendo algumas delas identificadas por Spinillo, Rego, Lima e Souza (2002) em histórias produzidas por crianças de oito anos de idade. No presente estudo, foram encontradas algumas dessas cadeias que são descritas a seguir e exemplificadas na Figura 1.

\begin{tabular}{ll}
\hline \multicolumn{1}{c}{ Cadeia coesiva } & Exemplos \\
\hline Repetição Integral & Mamãe $(M) \Rightarrow$ mamãe - mamãe - mamãe \\
Repetição Parcial & Mãe $(M) \Rightarrow$ mãe - mãe - mãe - mãe - mãe - mãe \\
Repetição Mista & Mãe $(M) \Rightarrow$ ela \\
Substituição por Referência & Bolo $(M) \Rightarrow$ biscoito - biscoito - mãe \\
Por sinonímia & Mamãe e Menina $(M) \Rightarrow$ pessoas \\
Substituição por hiperonímia & Mãe $(M) \Rightarrow$ Batínia - Batínia - Batínia - Batínia \\
Por nome próprio & Menina $(M) \Rightarrow$ ela - menina - filha - filha - filha - filha \\
Mista & - filha - filha \\
\hline
\end{tabular}

Nota. (M): palavra matriz na cadeia coesiva

Figura 1. Exemplos de cadeias coesivas identificadas no corpus de histórias analisado 
Tipo 1 - Cadeia por Repetição: repetição da matriz (M) através de um mesmo elemento lexical, podendo ocorrer de três formas:

Repetição integral: repetição da matriz sem alteração morfológica, de forma que o elemento repetido é idêntico à palavra matriz.

Repetição parcial: repetição da matriz com alteração morfológica, de forma que o elemento repetido não é idêntico ao elemento matriz, embora apresente uma equivalência semântica e mantenha a mesma base morfológica da palavra matriz.

Repetição mista: a cadeia é formada por elementos que são uma repetição integral da palavra matriz, enquanto outros são uma repetição parcial.

Tipo 2 - Cadeia por Substituição: variações lexicais que substituem um elemento anteriormente mencionado por outro. Neste estudo tais substituições ocorreram de quatro formas:

Por referência: substituição da matriz por pronome pessoal ou de duas matrizes por um mesmo pronome pessoal.

Por sinonímia: substituição da matriz por uma palavra com significado equivalente.

Por hiperonímia: substituição da matriz por uma palavra de classe superordenada.

Por nome próprio: substituição da matriz por um nome próprio.

Tipo 3 - Cadeia Mista: envolve a repetição e a substituição da matriz.

Como exemplo dessas cadeias em um texto, considerar a história escrita por um surdo oralizado apresentada na Figura 2.

Cadeia 1: Mamãe (M) ${ }^{\circledR}$ mamãe - mamãe - mamãe.

Caracterização: constituída por quatro elementos (uma matriz e três referentes). A palavra mamãe é a matriz, sendo repetida ao longo do texto através de um elemento lexical (mamãe) idêntico à palavra matriz; formando assim uma cadeia coesiva por repetição integral.

Cadeia 2: Biscoito (M) ® biscoito - bolo - biscoito biscoitos - bolo - biscoito - biscoito - biscoito.

Caracterização: formada por nove elementos (uma matriz e oito referentes). A matriz (biscoito) é repetida de forma idêntica em algumas partes do texto, sendo também substituída por um sinônimo (bolo) ${ }^{5}$. Trata-se, portanto, de uma cadeia coesiva mista.

Cadeia 3: Menina (M) ${ }^{\circledR}$ menina - menina - menina.

Caracterização: constituída por quatro elementos lexicais (uma matriz e três referentes), a matriz (menina) é repetida de forma idêntica ao longo do texto, formando assim uma cadeia coesiva por repetição integral.

\section{A estrutura narrativa das histórias}

Estrutura ou esquema narrativo é termo que se refere a um conjunto de elementos específicos e organizados que caracterizam um dado texto. No caso da história, sua estrutura corresponde aos elementos identificados e formalizados nas gramáticas de histórias (e.g., Brewer, 1985; Jonhson \& Mandler, 1980; Mandler \& Jonhson, 1977; Prince, 1973; Rumelhart, 1975; Stein, 1982; 1988; Stein \& Albro, 1997; Stein \& Glenn, 1979; Stein \& Policastro, 1984) que, apesar de variações, apresentam concordância quanto ao fato de que a estrutura de uma história prototípica constitui-se de: (a) início com uma abertura convencional (introdução da cena: informações sobre o tempo e lugar; personagens: suas características, motivações e metas a alcançar); (b) meio (evento, trama, situação-problema); e (c) final (resolução da situaçãoproblema) com um fechamento convencional.

Com base nessas gramáticas, analisou-se a estrutura narrativa das histórias escritas, procedendo-se a uma adap-

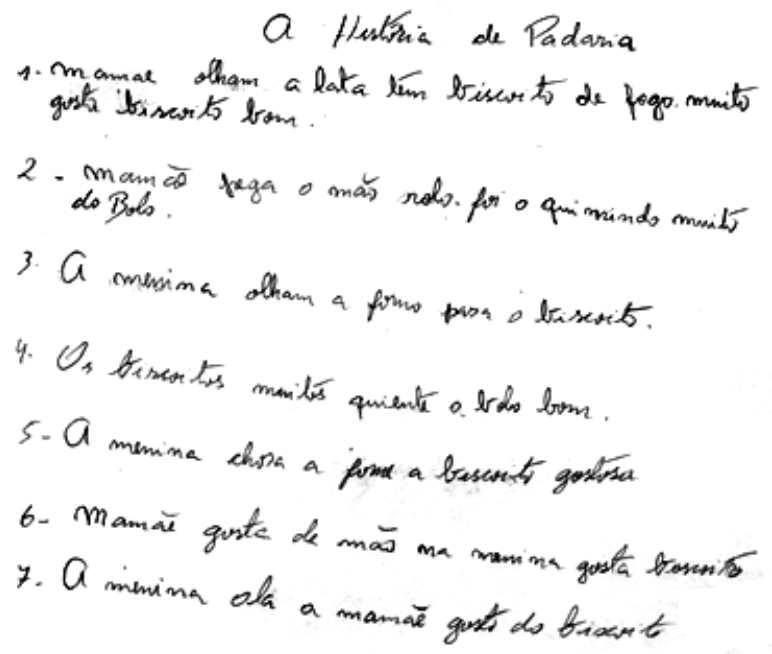

Figura 2. História escrita por um surdo oralizado. 


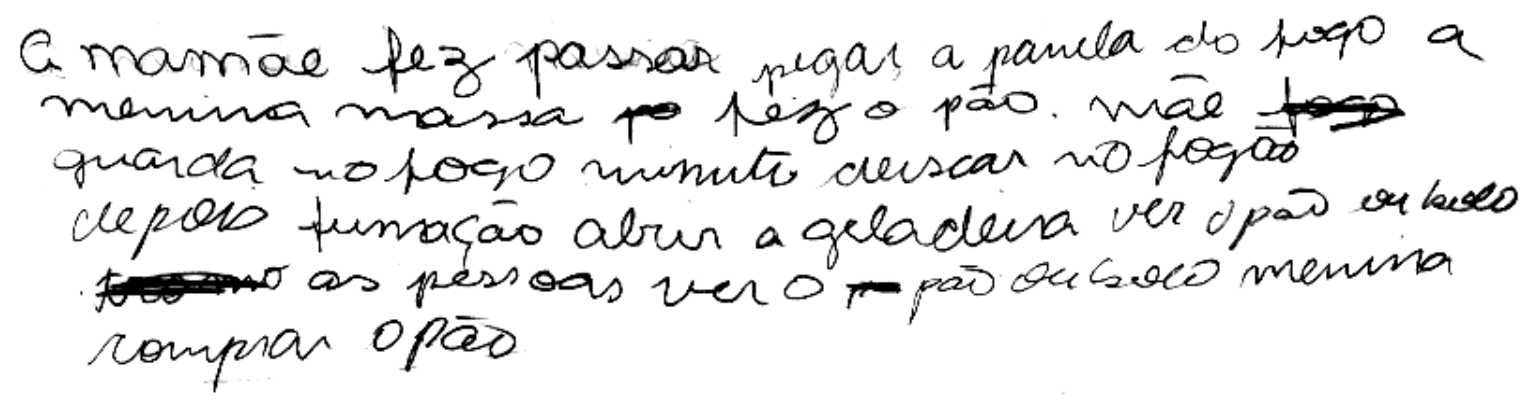

Figura 3. Exemplo de história escrita por surdo oralizado.

tação do sistema de categorias adotado por Spinillo (1991; 1993; 1996; Lins e Silva \& Spinillo, 2000; Spinilo \& Pinto, 1994) a partir do estudo original de Rego (1986) conduzido com crianças ouvintes. Três categorias foram identificadas:

Categoria I: a história se restringe a uma introdução da cena e dos personagens, descreve ações que se sucedem, sem especificar a situação-problema e sua resolução (Figura 3).

Categoria II: a história introduz a cena e os personagens, fornece indícios sobre a situação-problema, porém esta não é claramente especificada. O desfecho está ausente (Figura 4).

Categoria III: além da introdução da cena e dos personagens, a história apresenta claramente a situação-problema. Observa-se a presença de um desfecho que pode ou não especificar como a situação-problema é resolvida (Figura 5 e Figura 6, respectivamente).
Este sistema de análise caracteriza-se pela presença ou ausência dos componentes estruturais de histórias e não pelo uso de convenções lingüísticas próprias deste gênero de texto, como previsto no sistema de análise de Rego (1986) e Spinillo (1996), que envolvia ambos os aspectos. Esta adaptação foi feita devido ao fato de que em nenhuma das produções estavam presentes as convenções lingüísticas típicas de abertura (Era uma vez...) e de fechamento (... e foram felizes para sempre) de história.

\section{Resultados}

As cadeias coesivas

Um total de 86 cadeias coesivas foram produzidas, em sua maioria caracterizadas por repetição (Tipo 1: 72,1\%), sen-

\section{a mamaie fillha de menina}

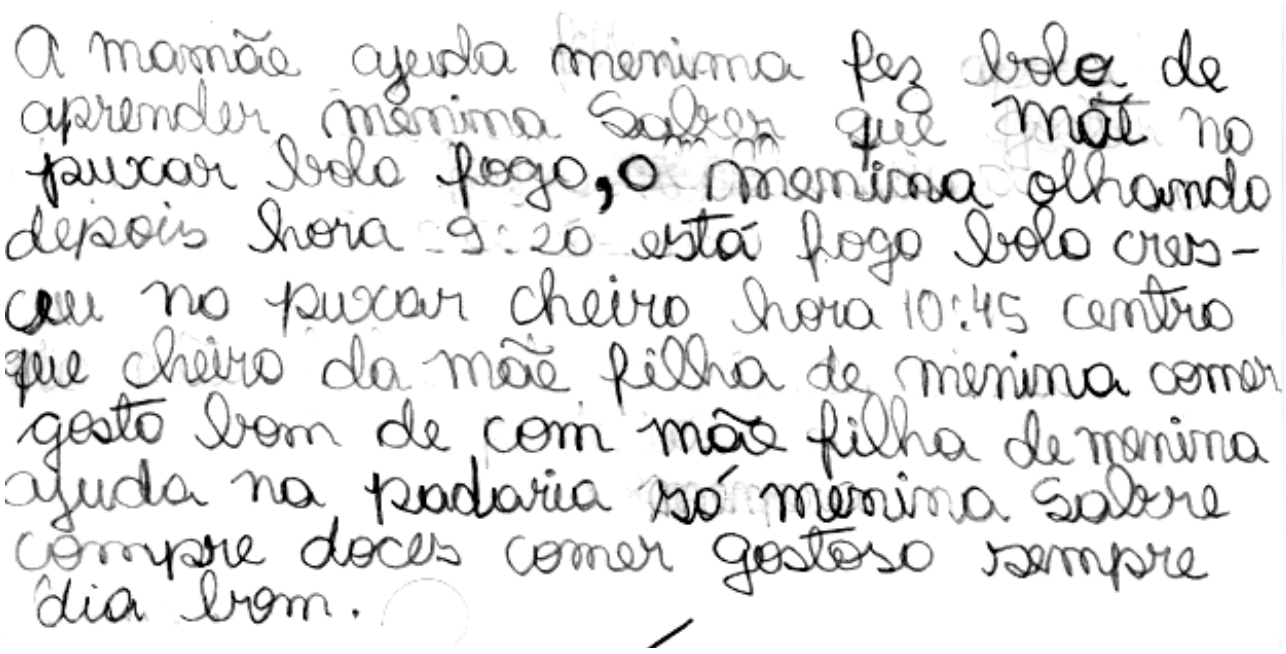

Figura 4. Exemplo de história escrita por surdo usuário da LIBRAS. 


\section{Historia}

A móe. nome e' Fernada, minha filha norre é tracy, a Fernda fazendo uma bolo para a vender, tracy muito me ayuola uma fa zendo a bolo, porque puturo a tracy pode ser Dono de Badaria.

A Fernada bota do forno, tracy tazendo mola de Pas 2 molde, depois fique a pronta a bota de forno. Mos fui Quviman, a tracef ficau Choa porque é bueimou, Ealma tracy gente in padaria lomprar de Bolo, mais que Belieia.

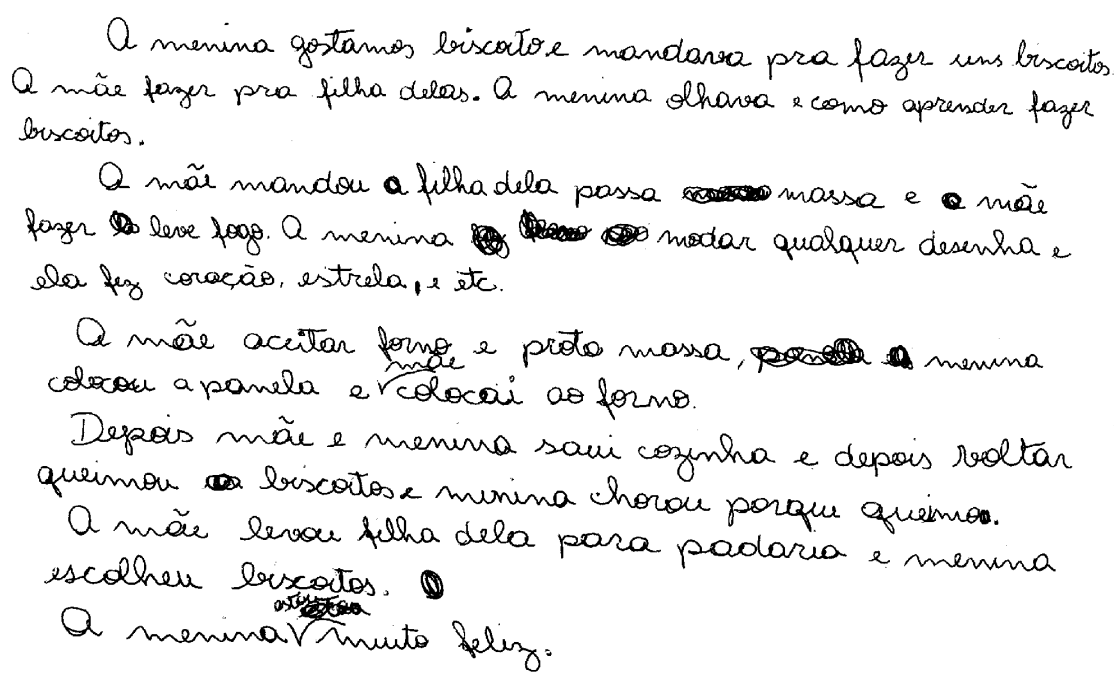

Figura 5. Exemplos de história escrita por usuários da LIBRAS e de história escrita por um surdo oralizado.

A. máe hazer cojinhno bisoscito al criancia Rolo Bandeja calacou Demorow minitos 15. Lica mä. Born ipgou logo'. orionea. picar chorar triste memino smá falou calma mavischorar e ma vai compra ajudé qualquies Socé tem Vontade pode memina Bistoito.

Figura 6. Exemplo de história que ilustra alguns dos aspectos comentados. 
do pouco freqüentes cadeias mistas (Tipo 3: 16,3\%) e cadeias por substituição (Tipo 2: 11,6\%).

Os grupos não se diferenciavam quanto ao número geral de cadeias coesivas (LIBRAS: 46; Oralizados: 40), e nem tampouco em relação a cada tipo de cadeia coesiva separadamente (Tabela 1), como revelado pelo teste T (valores de $p>$ 0,05 em cada tipo de cadeia). Isso indica que os dois grupos estabelecem cadeias coesivas de forma semelhante.

Tabela 1

Número e porcentagem de cada tipo de cadeia coesiva nos dois grupos de participantes

\begin{tabular}{lrrr}
\hline Tipos de cadeias coesivas & LIBRAS & Oralizados & \multicolumn{1}{c}{ Total } \\
\hline Tipo 1 - Repetição & $33(53,2)$ & $29(46,8)$ & 62 \\
Tipo 2 - Substituição & $8(80,0)$ & $2(20,0)$ & 10 \\
Tipo 3 - Mista & $5(35,7)$ & $9(64,3)$ & 14 \\
\hline
\end{tabular}

Embora a diferença não tenha sido significativa, os surdos usuários da LIBRAS tendiam a produzir mais cadeias coesivas por substituição (Tipo 2: 80\%) do que os oralizados (Tipo 2: 20\%); enquanto estes tendiam a estabelecer cadeias coesivas mistas (Tipo 3: 64,3\%) mais freqüentemente do que os usuários da LIBRAS (Tipo 3: 35,7\%).

$\mathrm{O}$ teste $\mathrm{T}$ foi também aplicado em relação aos diferentes subtipos de cadeias coesivas, como ilustra a Tabela 2. Não foram detectadas diferenças significativas entre os grupos em relação a nenhum dos tipos de cadeias coesivas produzidas (valores de $p>0,05$ ).

Note-se que a substituição por referência foi muito rara. Em todo o corpus de histórias analisado observou-se

Tabela 2

Número e porcentagem de cadeias coesivas presentes nas histórias dos dois grupos de participantes

\begin{tabular}{|c|c|c|c|}
\hline \multicolumn{2}{|c|}{ Cadeia Coesiva } & \multirow{2}{*}{$\begin{array}{r}\text { LIBRAS } \\
(\mathrm{n}=46)\end{array}$} & \multirow{2}{*}{ 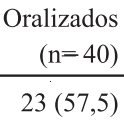 } \\
\hline Tipo 1 & Integral & & \\
\hline & Parcial & $05(10,9)$ & $02(5,0)$ \\
\hline & Mista & $01 \quad(2,2)$ & $04(10 \quad)$ \\
\hline \multirow{4}{*}{$\begin{array}{l}\text { Tipo } 2 \\
\text { Substituição }\end{array}$} & Por nome próprio & $03(6,5)$ & 0 \\
\hline & Por superordenação & $03(6,5)$ & $01(2,5)$ \\
\hline & Por sinonímia & $02(4,3)$ & 0 \\
\hline & Por referência & 0 & $01(2,5)$ \\
\hline $\begin{array}{l}\text { Tipo } 3 \\
\text { Mista }\end{array}$ & Mista & $05(10,9)$ & $09(22,5)$ \\
\hline
\end{tabular}

apenas um total de dez referências pessoais, das quais nove foram produzidas pelos surdos oralizados e apenas uma pelos surdos usuários da LIBRAS.

Além do percentual de cada tipo de cadeia coesiva, examinou-se, ainda, a presença dessas cadeias por história (Tabela 3).

Tabela 3

Número e porcentagem de histórias em que aparecem os diferentes tipos de cadeias coesivas (máximo: 20)

\begin{tabular}{lrr}
\hline \multicolumn{1}{c}{ Cadeias coesivas } & LIBRAS & Oralizados \\
\hline Repetição integral & $19(95)$ & $17(85)$ \\
Repetição parcial & $5(25)$ & $2(10)$ \\
Repetição mista & $1(5)$ & $4(20)$ \\
Substituição por nome próprio & $2(10)$ & 0 \\
Substituição por hiperonímia & $3(15)$ & $1(5)$ \\
Substituição por sinonímia & $2(10)$ & 0 \\
Substituição por referência & 0 & $1(5)$ \\
Mista & $4(20)$ & $7(35)$ \\
\hline
\end{tabular}

Cadeias coesivas por repetição estavam presentes na grande maioria das histórias em ambos os grupos (LIBRAS: 95\%; Oralizados: 85\%). A média em cada um dos grupos foi de duas cadeias coesivas por história. Esta é uma média inferior àquela observada entre crianças ouvintes (8 anos), como mostrado por Spinillo et al. (2002), que detectaram uma média de quatro cadeias coesivas por histórias; portanto, o dobro da média observada entre os adolescentes surdos.

\section{A estrutura narrativa das histórias}

As histórias foram classificadas em uma das três categorias de produção descritas anteriormente. Dois juizes independentes procederam à classificação, obtendo-se um percentual de $87,5 \%$ de concordância entre eles. Os casos de discordância foram analisados por um terceiro juiz, também independente, cuja classificação foi considerada final, coincidindo sempre com a classificação de um dos dois primeiros juizes. Os julgamentos eram cegos, no sentido em que ao analisar cada história os juizes desconheciam se a mesma havia sido produzida por um surdo oralizado ou por um usuário da LIBRAS.

Como indicado na Tabela 4, as histórias em toda a amostra caracterizam-se por produções elementares (Categoria I: 60\%).

As produções dos dois grupos se concentraram na Categoria I, como indicado pelo Qui-Quadrado aplicado a cada amostra separadamente (oralizados: $\chi^{2}=5,2 ; g l=2 ; p=$ 0,0074); e LIBRAS: $\left.\chi^{2}=12,1 ; g l=2 ; p=0,002\right)$. No entanto, apesar dessa similaridade entre os grupos, é possível detectar algumas diferenças entre eles, como pode ser visto na Tabela 4. Observa-se que os surdos oralizados produziam mais histórias na categoria mais elaborada (Categoria III: 40\%) 
Tabela 4

Número e porcentagem de histórias em cada categoria de produção e em cada grupo

\begin{tabular}{crrr}
\hline $\begin{array}{c}\text { Categorias de } \\
\text { produção }\end{array}$ & Oralizados & LIBRAS & Total \\
\hline I & $10(50)$ & $14(70)$ & $24(60)$ \\
II & $2(10)$ & $3(15)$ & $5(12,5)$ \\
III & $8(40)$ & $3(15)$ & $11(27,5)$ \\
\hline
\end{tabular}

do que os usuários da LIBRAS (Categoria III: 15\%). Além disso, estes produziam mais histórias na categoria elementar (Categoria I: 70\%) do que os surdos oralizados (Categoria I: 50\%).

\section{Comentários sobre outros aspectos observados}

Embora não tenham sido objeto de uma análise mais específica nesta investigação, alguns aspectos merecem ser comentados a respeito da produção escrita de histórias na população investigada.

Importante notar que em nenhuma das produções observou-se o uso do artigo indefinido para introduzir personagens que apareciam pela primeira vez na história. O esperado em histórias, como enfatizado por Rego (1986), é que seja utilizado o artigo indefinido quando mencionado um personagem pela primeira vez e depois o artigo definido em relação a este personagem já introduzido (exemplo: “ Era uma vez um menino chamado Carlos. Um dia o menino foi brincar e ...”).

As histórias, em geral, eram compostas por sentenças curtas com uma estrutura sintática elementar (Figura 2). Notou-se, ainda, que o uso de elementos de ligação (conjunções, preposições, pronomes possessivos e demonstrativos) era bastante limitado. Problemas também foram identificados em relação à flexão dos verbos. Tais comentários aplicam-se a ambos os grupos de participantes.

O uso de marcas de pontuação era bastante restrito, havendo casos em que tais marcas estavam ausentes como mostram a Figura 2 e a Figura 3. Quando presentes, as marcas de pontuação se limitavam ao ponto final, à vírgula e à exclamação; sendo o ponto final a pontuação mais empregada. Ao que parece, como ocorre com crianças ouvintes em idades entre 5-6 anos, as pontuações no interior das frases são marcas mais difíceis de serem produzidas do que aquelas que aparecem ao final das frases (ponto final, exclamação, interrogação). Nem sempre uma pontuação final era seguida de letra maiúscula para indicar o início de uma nova frase (Figura 6); e a vírgula, muitas vezes, era empregada de forma inadequada (primeira história na Figura 5).

\section{Conclusões e comentários finais}

A escrita é atividade humana que pode ser considerada a partir de inúmeras perspectivas. Pontecorvo (1997) faz uma distinção importante em relação à escrita: (1) a escrita da linguagem: escrita tomada como o processo de traçar símbolos em uma superfície material (papiro, pergaminho, papel, etc.), estando relacionada aos sistemas de escrita (escrita de palavras, aspectos ortográficos) e seus aspectos notacionais; e (2) a linguagem escrita: escrita enquanto processo de produzir textos, relacionado à escrita de unidades lingüísticas maiores como o texto e seus gêneros. É nessa segunda perspectiva que se inseriu o presente estudo.

No caso da produção de histórias, como enfatizado por Spinillo (2001, p. 73), existe uma infinidade de maneiras de se olhar as histórias produzidas por crianças. Por exemplo, podemos voltar nossa atenção para o conteúdo/tema tratado com o objetivo de compreender o que a história revela da vida emocional da criança, sua criatividade e fantasia, sua interpretação do mundo, suas representações sobre ele. Podemos, também, dirigir nosso interesse para compreender os aspectos que motivam o narrador a contar uma história, sua intenção comunicativa ou os processos de construção do texto. Podemos, ainda, examinar a estrutura da história produzida, a maneira como as idéias são relacionadas e conectadas ao longo do texto ou como a continuidade de sentidos é garantida.

A presente investigação tratou do exame da estrutura e da coesão textual em histórias escritas por adolescentes surdos usuários de formas distintas de comunicação: surdos oralizados e surdos usuários da língua dos sinais (LIBRAS). Além de analisar as peculiaridades da escrita de textos por esta população, procurou-se também examinar se a modalidade de língua por eles adotada seria fator importante que viesse a influenciar a produção escrita de textos. Tendo em vista esses dois aspectos, são apresentadas e discutidas as principais conclusões derivadas deste estudo.

\section{Como os surdos estabelecem a coesão textual em suas histórias}

Como comentado por Góes (1996), os surdos têm grande dificuldade com a referencialidade, sendo este fato constatado nesta investigação em relação ao uso pouco freqüente de referências pessoais (cadeia coesiva por substituição por referência). Nota-se que a ausência de referências parece ser compensada pelo estabelecimento de cadeias coesivas do tipo repetição integral da palavra matriz que era literalmente repetida diversas vezes. É possível que isso ocorra como uma estratégia lingüística adotada para tentar manter a coesão textual, como observado também nas narrativas produzidas por escritores iniciantes ouvintes, como mostrado por Spinillo et al. (2002). Esses dados foram igualmente encontrados em relação aos dois grupos investigados, concluindo-se que a produção de elos de ligação é um problema para os surdos quer sejam eles usuários da língua portuguesa oral ou da LIBRAS, não se podendo atribuir, portanto, uma interferência específica de umas dessas formas de comunicação sobre o estabelecimento de cadeias coesivas. Ao que parece, faltam aos surdos informações que permitam compreender o significado e a função desses elos de ligação na produção escrita. Os fatores responsáveis pela falta dessas informações precisam ser especificados.

Entretanto, mesmo adotando a repetição como estratégia lingüística, a articulação do texto ${ }^{6}$ não era garantida, o 
que comprometia sua compreensibilidade; sendo difícil interpretá-lo sem o apoio da seqüência de gravuras a partir da qual a história havia sido produzida. Fato semelhante foi verificado por Spinillo (1991; 1993; Spinillo \& Pinto, 1994) com crianças que não dominavam a produção de histórias, as quais tendiam a produzir textos que eram mais dependentes do recurso pictográfico (gravuras) do que da lexicalização, o que comprometia a compreensibilidade dos textos. Esta dificuldade foi também documentada por Góes (1996), sugerindo que a dificuldade dos surdos em estabelecer a coesão textual compromete a inteligibilidade do texto.

\section{Como se caracterizam as histórias escritas por surdos quanto à estrutura narrativa}

Quanto à estrutura narrativa, ambos os grupos estão longe de apresentar um domínio dos aspectos lingüísticos que caracterizam o estilo da escrita de histórias e do esquema narrativo próprio deste gênero. As histórias se caracterizavam por: (a) ausência de convenções lingüísticas de abertura e de fechamento próprias desse gênero (“Era uma vez...”, “... e foram felizes para sempre”); (b) ausência do uso do artigo indefinido para introduzir personagens que aparecem pela primeira vez no texto e o posterior uso do artigo definido; (c) um caráter mais descritivo que narrativo (descrição dos personagens, do ambiente físico); (d) fragmentações que dificultavam a construção de uma cadeia narrativa clara, isto é, a articulação do texto estava comprometida; e (e) ausência de uma situação-problema claramente especificada e sua resolução.

Tais dificuldades são encontradas, também, entre crianças ouvintes que ainda não desenvolveram plenamente a habilidade de produzir histórias. É provável que isso ocorra em conseqüiência do pouco contato que os surdos têm com textos escritos, como sugerido por Góes (1996) e por Fernandes (1990).

Importante mencionar que apesar de haver sido apresentada como estímulo uma seqüência de gravuras que continha uma situação-problema, este aspecto não mobilizou o surgimento de histórias elaboradas e nem evitou que muitos dos participantes simplesmente produzissem textos que se limitavam a uma descrição das gravuras ao invés de textos que apresentassem um enredo, uma cadeia narrativa articulada. A situação-problema representada nas gravuras não foi suficiente para provocar o aparecimento de uma situaçãoproblema que fosse claramente especificada no texto, e nem tampouco propiciou o aparecimento de ações, realizadas pelos personagens, orientadas para uma meta com vistas à resolução da situação problema. Pelo exposto, os surdos não parecem se beneficiar de uma seqüência de gravuras que representa uma situação-problema, como ocorre com crianças ouvintes (Lins e Silva \& Spinillo, 2000; Shapiro \& Hudson, 1997).

\section{Em que diferem as histórias produzidas por surdos oralizados e por usuários da LIBRAS}

Quanto ao estabelecimento da coesão através de cadeias coesivas, os dados mostraram que este aspecto da textualidade é um problema para os surdos oralizados e para os usuários da LIBRAS, não se verificando diferenças entre eles quanto a este aspecto.

A única diferença encontrada entre os dois grupos foi em relação à estrutura narrativa das histórias. Apesar das limitações mencionadas, um maior número de surdos oralizados produzia historias mais elaboradas do que os usuários da LIBRAS. Talvez, por usarem o português oral, os surdos oralizados tenham um maior contato com a linguagem dos textos do que os surdos usuários da LIBRAS que se comunicam através de uma língua distinta daquela em que os textos são escritos. Um contato mais freqüente com textos escritos pode gerar aquisições importantes relativas à textualidade. Entretanto, esta afirmação deve ser considerada com cautela, visto que, nesta investigação não foi feito um exame da freqüência e tipo de contato que os participantes da amostra tinham com textos em seu cotidiano (na escola e na família). Seria interessante realizar um estudo que examinasse as relações entre contato com textos e produção textual em surdos. É possível que fosse identificada uma correlação entre a qualidade das produções e o contato com textos em casa e na escola: surdos com um alto nível de contato com textos diversos talvez sejam mais competentes na produção de textos coesos, articulados e coerentes do que surdos com um contato restrito com textos.

\section{Implicações educacionais}

A partir das discussões de Vygotsky (1993) sobre desenvolvimento psicológico e deficiência, ressalta-se a idéia de que a educação da criança com alguma dificuldade ou limitação deve atender às mesmas metas propostas para a criança “não deficiente”. No entanto, para propiciar oportunidades de desenvolvimento da linguagem e acesso a conhecimentos sistematizados, faz-se necessário oferecer “caminhos especiais” a esta criança. No caso dos surdos, isso significa que as metas devem ser as mesmas, porém, os caminhos de acesso precisam ser diferentes daqueles adotados com crianças ouvintes, de forma a permitir que sejam alcançados níveis de desenvolvimento satisfatórios dentro da limitação imposta pela dificuldade auditiva. Exemplos desses caminhos especiais são apresentados nos estudos de caso de Silvia e Elena anteriormente relatados.

Assim, no que concerne à produção de textos, o desafio daqueles que se voltam para a educação dos surdos é criar estratégias de ensino que levem estes indivíduos a produzir textos mais coesos e com uma estrutura narrativa mais elaborada de maneira que seus textos sejam compreendidos. Aumentar o contato dos surdos com textos escritos (tanto na produção como na compreensão) é uma alternativa, chamando a atenção para o papel desempenhado pelos coesivos em um texto e chamando a atenção para a estrutura e convenções lingüísticas próprias do estilo narrativo de histórias. Os métodos de ensino, no entanto, estão longe de atender plenamente às necessidades dos surdos de maneira a auxiliá-los a superar suas limitações frente a esses aspectos da textualidade.

Estudos de intervenção poderiam ser conduzidos em que o examinador ou o próprio professor criasse oportunida- 
des de reflexão acerca dos elementos que compõem uma história e das convenções lingüísticas que a caracterizam. É possível que uma intervenção deste tipo viesse a trazer progressos na produção de histórias em crianças e adolescentes surdos. Uma intervenção desta natureza foi realizada por Ferreira (1999) com crianças ouvintes que, após receberem intervenções voltadas para o desenvolvimento da consciência metatextual, apresentaram um expressivo desenvolvimento da produção oral de historias.

O importante é desenvolver as habilidades textuais dos surdos, diminuindo a distância entre eles e os ouvintes quanto a este aspecto. Isso se torna crucial quando se considera o papel de destaque conferido ao texto no processo educacional, como enfatizado amplamente nos PCN de Língua Portuguesa (Brasil, 1997), não se devendo deixar os indivíduos surdos à margem deste processo. Desenvolver a habilidade de produzir textos é tornar os surdos aptos para a comunicação através da escrita, instrumento este de inegável importância social, lingüística e cognitiva.

\section{Agradecimentos}

A pesquisa recebeu apoio do $\mathrm{CNPq}$ sob forma de bolsa concedida à primeira autora para estudos de mestrado. As autoras agradecem a Virgínia Colares e a Glória Carvalho pelos comentários valiosos feitos a respeito deste trabalho. Agradecimentos especiais são endereçados aos participantes desta pesquisa, e às escolas e centros especializados que tornaram possível a coleta de dados.

\section{Referências}

Almeida, E. O. C. (2000). Leitura e surdez: um estudo com adultos não oralizados. Rio de Janeiro: Revinter.

Antunes, M. I. C. M. (1996). Aspectos da coesão do texto: uma análise em editoriais jornalísticos. Recife: Editora Universitária da UFPE.

Brandão, A. C. P., \& Spinillo, A. G. (2001). Produção e compreensão de textos em uma perspectiva de desenvolvimento. Estudos de Psicologia, 6(1), 5162.

Brasil (1997). Parâmetros Curriculares Nacionais - Língua Portuguesa. Brasília: Secretaria de Educação Fundamental.

Brewer, W. (1985). The story schema: universal and culture-specific properties. In D. R. Olson, N. Torrance, \& A. Hildyard (Orgs.), Literacy, language and learning (pp. 167-194). Cambridge: Cambridge University Press.

Caquette, C. (1973). Étude longitudinale du dévelopment mental d ${ }^{\prime}$ énfants sourd. Bulletin de Psychologie, 27, 262-275.

Conte, M. P., Rampelli, L. P., \& Valterra, V. (1996). Deaf children and the construction of written texts. In C. Pontecorvo, M. Orsolini, B. Burge, E. Lawrence, \& B. Resnick (Orgs.), Children's early text construction (pp. 303-319). Mahwah: Lawrence Earlbaum Associates.

Cordeiro, A. A., \& Dias, M. G. B. B. (1995). O raciocínio lógico-dedutivo do surdo que se utiliza da linguagem gestual ou oral. Psicologia: Teoria e Pesquisa, 11(3), 193-202.

Dorziat, A. (1997). Metodologias específicas ao ensino de surdos: análise crítica. Programa de Capacitação de Recursos Humanos do Ensino Fundamental, Deficiência Auditiva (Vol. I, pp. 299-308). Brasília: Secretaria de Educação Especial -MEC.

Fávero. L. L., \& Koch, I. G. V. (2000). Lingüística textual: introdução. São Paulo: Cortez.
Felipe, T. A. (1988). O signo gestual-visual e sua estrutura frasal na língua dos sinais dos centros urbanos do brasil (LSCB). Dissertação de mestrado nãopublicada, Universidade Federal de Pernambuco, Recife.

Felipe, T. A. (1998). Introdução à gramática da LIBRAS. Programa de Capacitação de Recursos Humanos do Ensino Fundamental, Língua Brasileira de Sinais (Vol. III, pp. 81-107). Brasília: Secretaria de Educação Especial -MEC.

Fernandes, E. (1990). Problemas lingüísticos e cognitivos do surdo. Rio de Janeiro: Agir.

Fernandes, E. (1997). Surdez e bilingüismo: leitura de mundo e mundo da leitura. Programa de Capacitação de Recursos Humanos do Ensino Fundamental, Deficiência Auditiva (Vol. I, pp. 309 - 331). Brasília: Secretaria de Educação Especial -MEC.

Ferrari, L. V.(1990). Aspectos da interferência da língua dos sinais na produção do português. Revista GELES, 4(4), 12-21.

Ferreira, A. L. (1999). Produção e consciência metalingüística de textos em crianças: um estudo de intervenção. Dissertação de mestrado não-publicada, Universidade Federal de Pernambuco, Recife.

Ferreira Brito, L. (1989). Classificadores em LSCB. Anais do IV Encontro Nacional da ANPOLL (pp. 640-654). Recife.

Ferreira Brito, L. (1990). O discurso ideológico das filosofias educacionais para surdos e sua língua dos sinais. Revista GELES, 4(4), 22-44.

Ferreira Brito, L. (1995). Por uma gramática da língua de sinais. Rio de Janeiro: Tempo Brasileiro.

Ferreira Brito, L. (1998). Língua Brasileira de Sinais - LIBRAS. Programa de Capacitação de Recursos Humanos do Ensino Fundamental, Língua Brasileira de Sinais (Vol. III, pp. 19-61). Brasília: Secretaria de Educação Especial -MEC.

Góes, M. C. R. (1996). Linguagem, surdez e educação. Campinas: Autores Associados.

Guimarães, E. (2001). A articulação do texto. São Paulo: Ática.

Halliday, M. A. K., \& Hasan, R. (1976). Cohesion in English. Londres: Longman.

Hudson, J. A., \& Shapiro, L. R. (1991). From knowing to telling: the development of children's scripts, stories, and personal narratives. In A. McCabe \& C. Peterson (Orgs.), Developing narrative structure (pp. 89-136). Hillsdale: Lawrence Erlbaum Associates.

Johnson, N. S., \& Mandler, J. M. (1980). A tale of two structures: underlying and surface forms in stories. Poetics, 9, 51-86.

Koch, I. G. V. (1989). A coesão textual. São Paulo: Contexto.

Lins e Silva, M. E., \& Spinillo, A. G. (2000). A influência de diferentes situações de produção na escrita de histórias. Psicologia: Reflexão e Crítica, 13(3), 337-350.

Mandler, J. M., \& Johnson, N. S. (1977). Remembrance of things parsed: story structure and recall. Cognitive Psychology, 9, 111-151.

Marcuschi, L. E. (1983). Lingüística de texto: como é e como se faz (Séries Debates 1), Universidade Fedral de Pernambuco, Mestrado em Letras e Lingüística, Recife,

Moura, M. C. (2000). O surdo: caminho para uma nova identidade. Rio de Janeiro: Revinter.

Pontecorvo, C. (1997). Studying writing and acquisition today: a multidisciplinary view. In C. Pontecorvo (Org.), Writing development: an interdisciplinary view (pp. xv-xxxi). Philadelphia: John Benjamins.

Prince, G. (1973). A grammar for stories. The Hague: Mouton.

Rego, L. B. (1986). A escrita de histórias por crianças: as implicações pedagógicas do uso de um registro lingüístico. Revista de Documentação de Estudos em Lingüística Teórica e Aplicada, 2(2), 165-180.

Ruiz, N. T. (1997). A young deaf child explores punctuation. In N. Hall \& A. Robinson (Orgs.), Learning about punctuation (pp. 109-127). Philadelphia: Multilingual Matters.

Rumelhart, D. (1975). Notes on a schema for stories. In D. G. Bobrow \& A. Colling (Orgs.), Representation and understanding: studies in cognitive science (pp. 112-141). Nova York: Academic Press. 
Santos, L. H. M., \& Dias, M. G. B. B. (1998). Compreensão de textos em adolescentes surdos. Psicologia: Teoria e Pesquisa, 14(3), 241-249.

Schelesinger, H. S., \& Meadow, K. (1972). Sound and sign: childhood deafness and mental health. Berkeley: University of California Press.

Shapiro, R. L., \& Hudson, J. A. (1997). Coherence and cohesion in children's stories. In J. Costermans \& M. Fayol (Orgs.), Processing interclausal relationships: studies in the production and comprehension of text (pp. 2348). Mahwah: Lawrence Erlbaum Associates.

Spinillo, A. G. (1991). O efeito da representação pictográfica na produção de narrativas. Psicologia: Teoria e Pesquisa, 7(3), 311-326.

Spinillo, A. G. (1993). Era uma vez ... e foram felizes para sempre. Temas em Psicologia, 1, 67-87.

Spinillo, A. G. (1996). O uso de coesivos por crianças com diferentes níveis de domínio de um esquema narrativo. In M. G. B. B. Dias \& A. G. Spinillo (Orgs.), Tópicos em Psicologia Cognitiva (pp. 84-119). Recife: Editora da Universidade Federal de Pernambuco.

Spinillo, A. G. (2001). A produção de histórias por crianças: a textualidade em foco. In J. Correa, A. G. Spinillo, \& S. Leitão (Orgs.), Desenvolvimento da linguagem: escrita e textualidade (pp. 73-116). Rio de Janeiro: Nau Editora. Spinillo, A. G., \& Pinto, G. (1994). Children's narratives under different conditions: a comparative study. British Journal of Developmental Psychology, 12, 177-193.

Spinillo, A. G., Rego, F. B., Lima, E. B., \& Souza, N. (2002). A aquisição da coesão textual: uma análise exploratória da compreensão e da produção de cadeias coesivas. In A. G. Spinillo, G. Carvalho, \& T. Avelar (Orgs.),
Aquisição da linguagem: teoria e pesquisa. Recife: Editora da Universidade Federal de Pernambuco.

Stein, N. L. (1982). What's in a story: interpreting the interpretation of story grammar. Discourse Processes, 5, 319-335.

Stein, N. L. (1988). The development of children's storytelling skill. In M. Franklin \& S. Barten (Orgs.), Child language (pp. 282-298). Oxford: Oxford University Press.

Stein, N. L., \& Albro, E. R. (1997). Building complexity and coherence: children's use of goal-structured knowledge in telling stories. In M. Bamberg (Org.), Narrative development: six approaches. New Jersey: Lawrence Erlbaum Associates.

Stein, N. L., \& Glenn, C. G. (1979). An analysis of story comprehension in elementary school children. In R. O. Freedle (Org.), New directions in discourse processing. Advances in discourse processes (Vol. 2, pp. 53-120). Norwood: Ablex.

Stein, N. L., \& Policastro, M. (1984). The concept of a story: a comparison between children's and teacher's viewpoints. In H. Mandl, N. L. Stein, \& T. Trabasso (Orgs.), Learning and comprehension of text. Hillsdale: Lawrence Erlbaum Associates.

Stockoe, W. C. (1960). Sign language structure: an outline of the visual communication system of the American deaf. Maryland: Linstok Press.

Vygotsky, L. S. (1993). The fundamentals of defectology. Abnormal psychology and learning disabilities. The collected works of L. S. Vygotsky. Nova York: Plenum.

\section{Notas}

1 Este artigo faz parte da dissertação de mestrado da primeira autora, sob orientação da segunda, na PósGraduação em Psicologia da Universidade Federal de Pernambuco.

2 Ferreira Brito (1990; 1995; 1998) descreve a estrutura e os parâmetros característicos da LIBRAS.

3 Denominação adotada pela Federação Nacional de Educação e Integração dos Surdos (FENEIS) e pelo MEC.

4 A estrutura gramatical das línguas de sinais varia entre países, existindo, portanto, línguas de sinais diferentes. Uma mesma língua de sinais pode ser utilizada em dois países, como no caso da língua de sinais americana que é usada nos Estados Unidos e no Canadá. Entretanto, pode ocorrer o oposto: países de uma mesma língua oral adotarem línguas de sinais distintas, como é o caso de Brasil e Portugal.

5 A palavra bolo foi tomada, no texto produzido, como sendo sinônima da palavra biscoito.

6 A articulação do texto, como afirma Guimarães (2001), refere-se, fundamentalmente, às relações entre as frases no nível do sentido que fazem do texto um conjunto de informações que se seguem sobre um eixo de sucessividade.

Viviany Meireles, mestre em Psicologia pela Pós-Graduação em Psicologia da Universidade Federal de Pernambuco.

Alina Galvão Spinillo, doutora em Psicologia do Desenvolvimento pela University of Oxford, Inglaterra, com Pós-Doutorado na University of Sussex, Inglaterra, é pesquisadora na Pós-Graduação em Psicologia e professora adjunta do departamento de Psicologia da Universidade Federal de Pernambuco. Endereço para correspondência: Pós-Graduação em Psicologia, Universidade Federal de Pernambuco; CFCH, 8ํㅜ andar, Cidade Universitária; Recife, PE; CEP 50670-901. Fone: (81) 3271-8272. Fax: (81) 3271-1843. E-mail: spin@npd.ufpe.br 
Apêndice

Seqüência de gravuras utilizada (baseada em Shapiro \& Hudson, 1997)

Fig. 1

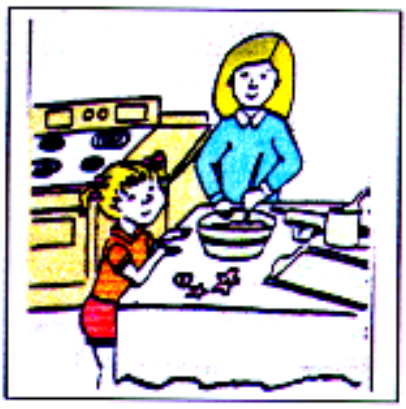

Fig. 3

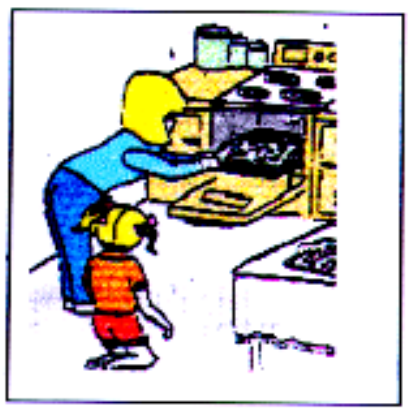

Fig. 5

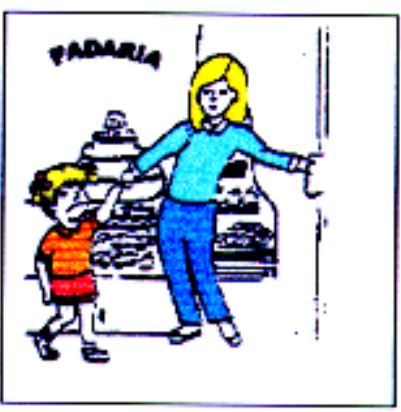

Fig. 2

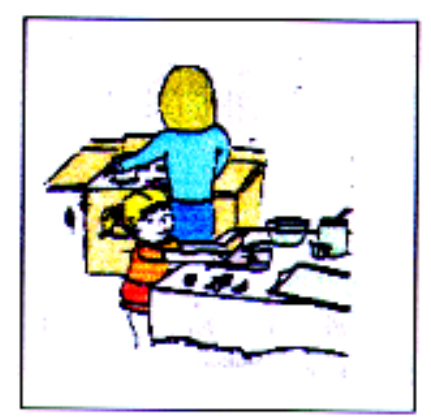

Fig. 4

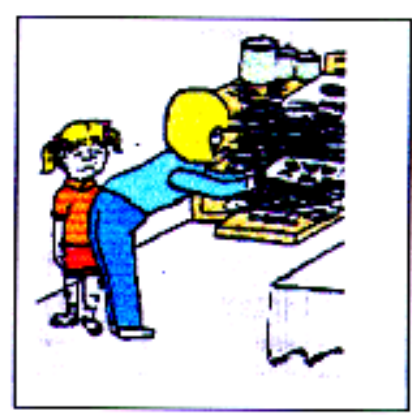

Fig. 6

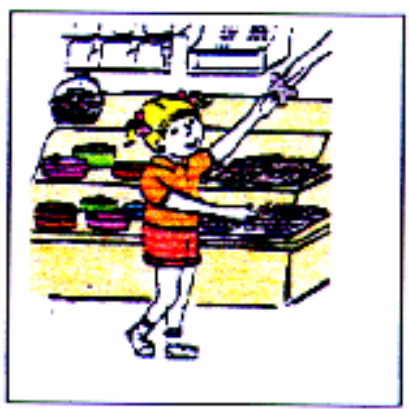

